\title{
Peer and sibling substance use: predictors of substance use among adolescents in Mexico
}

\author{
William Latimer, ${ }^{1}$ Leah J. Floyd, ${ }^{1}$ Tarmo Kariis, ${ }^{2}$ Gabriela Novotna, ${ }^{3}$ \\ Petra Exnerova, ${ }^{4}$ and Megan O’Brien ${ }^{1}$
}

Suggested citation Latimer W, Floyd LJ, Kariis T, Novotna G, Exnerova P, O'Brien M. Peer and sibling substance use: predictors of substance use among adolescents in Mexico. Rev Panam Salud Publica. 2004;15(4):225-32.

ABSTRACT Objective. To examine the extent to which peer drug use and sibling drug use predict alcohol abuse/dependence disorder status and the use of drugs other than alcohol among schoolbased youth in Mexico.

Methods. Data were collected on 1203 middle and high school students in northern Mexico in May 1998. Participation was voluntary, and responses were confidential. Logistic regression analyses estimated the association that peer drug use and that sibling drug use had with alcohol abuse/dependence diagnosis and the lifetime use of drugs other than alcohol.

Results. Students who had siblings or peers who used alcohol and other drugs were more likely to meet the standard alcohol abuse/dependence criteria defined by the Diagnostic and Statistical Manual of Mental Disorders Fourth Edition (DSM-IV), and were more likely to have used drugs other than alcohol. Controlling for potentially important confounders, we found that adolescents with the highest level of peer substance use were eight times as likely to meet alcohol abuse/dependence criteria and four times as likely to use other drugs. Youth who had siblings who used drugs were about twice as likely to meet alcohol abuse/dependence criteria and about 2.5 times as likely to use drugs other than alcohol when compared to youth with no sibling substance use.

Conclusions. Consistent with extant findings among youth in the United States of America, peer and sibling substance use are major risk factors for substance use among school-based youth in Mexico. Students in Mexico may benefit from prevention strategies found to be effective among students in the United States.

Key words Substance-related disorders, risk factors, students, adolescent, peer group, sibling relations, Mexico.

1 Johns Hopkins University, Baltimore, Maryland, United States of America. Send correspondence to: William Latimer, Johns Hopkins University Bloomberg School of Public Health, Department of Mental Health, 624 N. Broadway, Suite 794, Baltimore, Maryland 21205, United States of America; telephone: 410-287-2988; fax: 410-955-9088; e-mail: wlatimer@jhsph.edu

2 Estonia Foundation for Prevention of Drug Addiction, Tallinn, Estonia.
Adolescent substance use and abuse is a serious public health problem in a

\footnotetext{
3 Institute of Drug Dependencies, Centre for Treatment of Drug Dependence, Bratislava, Slovak Republic.
}

4 Ministry of Health, Praha, the Czech Republic. number of countries around the world (1-8). Similar to patterns of drug use evidenced by youth in the United States of America, adolescent substance abuse in Mexico has become a major concern during the last two decades $(4,5,8)$. In 1991 a nationwide survey of adolescent 
substance use among school-based youth in Mexico was conducted. Data from the survey indicated $74 \%$ of high school students residing in the northern region of Mexico reported lifetime use of alcohol, with more than $15 \%$ reporting monthly alcohol use (4).

While the prevalence of alcohol use among school-based youth in Mexico was similar to alcohol use rates exhibited by youth in the United States, use rates of marijuana and other illicit drugs were much lower among youth in Mexico $(5,6,9)$. For example, fewer than $1 \%$ of middle school youth in northern Mexico reported lifetime use of marijuana. Further, the prevalence of lifetime marijuana use did not exceed $4 \%$, even among high school students. The lifetime prevalences of drugs other than alcohol and marijuana that were used by middle school youth ranged from $0.2 \%$ for heroin to $2.4 \%$ for inhalants. Among high school students, lifetime prevalences for drugs other than alcohol and marijuana ranged from $0.2 \%$ for heroin to $3.2 \%$ for inhalants.

While rates of drug use may differ for certain substances when youth in Mexico are compared to youth in the United States, the adverse outcomes are alarmingly similar. Youth drug use and drug abuse are associated with a wide range of negative consequences in both Mexico and the United States, including school failure (2, 10-12), traffic fatalities (13), the spread of sexually transmitted diseases from unsafe sex $(14,15)$, and antisocial and criminal behavior as well as violence $(6,8,16,17)$.

With the goal of preventing morbidities and mortality associated with adolescent substance use, recent studies have sought to identify potentially malleable psychosocial factors that may have an etiological influence on adolescent substance use and abuse. A large base of research conducted with clinical and community-based samples in the United States has investigated a range of psychosocial risk and protective factors (16). Peer substance use and sibling substance use have repeatedly emerged as substantive risk factors of adolescent substance use (10, 18). Peer alcohol use and peer attitudes have been shown to exert a greater in- fluence on adolescent drinking behavior than do parental alcohol use attitudes (19). Several studies suggest that sibling substance use is a substantive predictor of the onset and severity of adolescent substance use $(1,19,20)$. In comparison to abstainers, youths who have experimented with drugs also were more likely to have fathers or brothers who had used drugs (5).

While many studies examining predictors of youth substance use have been conducted in the United States, comparable studies conducted in Mexico are less abundant. Nevertheless, similar to findings for the United States, findings from studies conducted in Mexico suggest that either having siblings who use drugs or associating with drug-using peers increases the risk of adolescent substance use and abuse $(8,21)$. For example, Medina-Mora and colleagues (5) found peer drug use to be an important predictor of drug use initiation among school-based youth in Mexico. In addition, associating with drug-using peers distinguished youth who had tried only one drug other than tobacco or alcohol from youth who were polydrug users $(5,8)$. Peer use also has been shown to be a substantive predictor of the progression from drug abuse to drug dependence among Mexican youth (6). The primary aim of this study was to replicate previous findings on the influences of peer and sibling substance use in a more recent sample of school-based youth in one region of Mexico. Given the high emigration rates to the United States from the northern border states of Mexico, it is important to understand the drug use patterns of youth from those border states. The identification of common drug abuse risk factors may result in drug prevention interventions that benefit a greater proportion of Mexican youth, including those who emigrate from Mexico to the United States.

\section{MATERIALS AND METHODS}

\section{Participants}

Using telephone directories, Ministry of Education resources, and the
Internet, two schools-one middle school and one high school-were randomly selected in Monclova, which is the third largest city in the Mexican northern border state of Coahuila. A total of 1227 youth in grades 7 through 12 completed the survey in May 1998. Fewer than $2 \%$ of the youths (24 of them) completing the survey were excluded from the final analyses because they had either endorsed use of a fictitious drug or had given inconsistent responses throughout the survey. The final sample of 1203 youth included $94 \%$ of the students enrolled in the middle school and $89 \%$ of the students enrolled in the high school. The 1203 youth were between the ages of 12 and 19 years (mean age $=15.09$; standard deviation $=1.68$ ), with a slightly higher proportion of males $(54.5 \%)$. A large majority of the youth $(79.3 \%)$ reported their ethnicity as Hispanic (hispano o latino), $11.9 \%$ were Native American (indígena o nativo americano), $1.8 \%$ were African-American (africano americano) and $7 \%$ identified themselves as other (otro). A detailed description of sample characteristics is provided in Table 1.

\section{Procedure}

On two occasions prior to the survey administration, a letter describing the aims and procedures was sent to the parents of all students enrolled in the participating schools. In addition, a third letter was sent home with student report cards approximately two weeks prior to the survey administration date. Students were given the option not to participate in the survey or to withdraw from the study at any time.

Teachers received a three-hour didactic session on standardized survey administration procedures from the project director. During this session, teachers were given a set of standardized instructions. which included verbatim statements to read aloud to students when administering the survey.

We followed a method adapted from the confidential survey procedure used during the Monitoring the Future study, an ongoing study of at- 
TABLE 1. Summary of characteristics of 1203 school-attending youth in study of substance abuse/dependence, northern Mexico, 1998

\begin{tabular}{lrr}
\hline \multicolumn{1}{c}{ Variable } & No. & $\%$ \\
\hline $\begin{array}{l}\text { Gender } \\
\text { Female }\end{array}$ & 656 & 54.5 \\
Male & 547 & 45.5 \\
Age (yr) & & \\
12 & 61 & 5.1 \\
13 & 186 & 15.5 \\
14 & 209 & 17.4 \\
15 & 253 & 21.0 \\
16 & 230 & 19.1 \\
17 & 160 & 13.3 \\
18 & 88 & 7.3 \\
19 & 16 & 1.3 \\
Ethnicity & & \\
Hispanic & & \\
Native American & 954 & 79.3 \\
African-American & 143 & 11.9 \\
Other & 22 & 1.8 \\
Grade & 84 & 7.0 \\
7 & & \\
8 & 224 & 18.6 \\
9 & 204 & 17.0 \\
10 & 191 & 15.9 \\
11 & 270 & 22.4 \\
12 & 167 & 13.9 \\
& 147 & 12.2 \\
\hline & & \\
\end{tabular}

titudes, behaviors, and values of secondary school students, college students, and young adults in the United States (22). Because this was a longitudinal study, we asked students to provide identifying information on a cover page. To safeguard confidentiality, prior to completing the survey, students detached the page with the identifying information and passed this cover page to their teachers, who placed it in an envelope that was sealed. The project director and project coordinator collected the sealed envelopes containing each student's single page of identifying information while the students began to complete the survey. To further safeguard confidentiality, teachers were instructed not to answer specific student questions. The project director and project coordinator were both on site during the survey administration and circulated from class to class to address questions. Parents and students were made aware that providing the requested identifying information would enable the researchers to confidentially match student identities to the information provided on the survey. Information from the cover page was used to link baseline survey responses with follow-up survey responses. Including students who discontinued after beginning the survey, fewer than $1 \%$ of the parents or students from the two schools elected not to participate in the survey. The study survey and procedures were approved by the Monclova Superintendent of Schools; an ad hoc review board convened at each participating school, comprised of the principal, teachers, and parents; and the University of Minnesota Institutional Review Board.

\section{Measures}

Measures for the current study were derived from the Spanish-language version of the International Longitudinal Survey of Adolescent Health (23), which included items derived mainly from the Adolescent Diagnostic Interview (ADI) (2) and the Personal Experience Inventory (PEI) (24). The ADI is a multiaxial structured interview designed to assess substance use disorders among youth, according to criteria of the Diagnostic and Statistical Manual of Mental Disorders Fourth Edition ("DSM-IV"), which is the main diagnostic reference manual of mental health professionals in the United States. The PEI is a self-administered questionnaire designed to examine the frequency of adolescent substance use, psychological substance dependence, and psychosocial risk factors $(24,25)$.

\section{Alcohol abuse/ dependence disorders}

Survey items taken mainly from the ADI assessed DSM-IV diagnostic criteria for alcohol abuse and dependence. A total of 11 items assessed the four DSM-IV diagnostic criteria of alcohol abuse, and a total of 11 separate items assessed the seven DSM-IV diagnostic criteria for alcohol dependence. All alcohol abuse and dependence items assessed whether specific events (e.g., "Have you tried, unsuccessfully, to cut down on alcohol or stop drinking?") had occurred during the past 12 months. Alcohol abuse or dependence disorder status was determined using diagnostic algorithms established for the ADI following DSM-IV criteria (26). To meet alcohol dependence criteria, youth had to endorse at least three survey items that cut across at least three of the seven dependence criteria. To meet alcohol abuse criteria, youth had to endorse one or more survey items that addressed any one of the four DSM-IV criteria for alcohol abuse. For the entire sample, a total of 93 youth $(7.7 \%)$ met diagnostic criteria for alcohol abuse/dependence. The youth meeting alcohol abuse/dependence criteria reported using alcohol more than 20 times during their lifetime. In contrast, youth not meeting diagnostic criteria typically reported having used alcohol fewer than 2 times in their lifetime, with many of them reporting never having used alcohol.

\section{Frequency of other illicit drug use}

Survey items derived from the PEI assessed lifetime use frequencies for illicit drugs, including marijuana and hashish, LSD, psychedelics other than LSD, cocaine, amphetamines, barbiturates, tranquilizers, heroin, narcotics other than heroin, and inhalants. To measure substance use during the respondent's lifetime, substance use frequency items had seven response options, ranging from never to 40 or more times. Out of the 1203 youth, 1051 of them $(87.4 \%)$ reported never having used illicit drugs other than alcohol in their lifetime, while 73 youth $(6.1 \%)$ reported using other illicit drugs 1 or 2 times in their lifetime. The remaining 79 youth comprising the sample $(6.6 \%)$ reported using other illicit drugs 3 or more times in their lifetime. A dichotomous variable was derived that distinguished between the 1124 youth (93.4\%) who reported using other illicit drugs either never or 1 or 2 times in 
their lifetime from the 79 youth $(6.6 \%)$ who reported using other illicit drugs 3 or more times in their lifetime.

\section{Peer drug use}

Survey items derived from the psychosocial section of the PEI assessed peer drug use and sibling drug use among the adolescent respondents. Peer drug use was assessed with five items (e.g., "Some kids I hang around with use alcohol or drugs before or during school.") that had four response options, ranging from "strongly disagree" to "strongly agree." A peer drug use scale was derived from the sum of individual items, with the sum having a range of 0 to 15 (alpha $=.64$ ). Categorical variables for peer drug use corresponding approximately to quartiles on the continuous peer drug use measure were derived. A total of 420 youth $(34.9 \%)$ had peer drug use scale scores of " 0 ," and they were assigned to the "no peer drug use risk" category, which served as the referent group in logistic regressions. The 298 youth $(24.8 \%)$ whose scores were either " 1 " or " 2 " on the peer drug use scale were assigned to the "low peer drug use risk" category. The 231 youth (19.2\%) whose scores were either " 3 " or " 4 " on the peer drug use scale were assigned to the "medium peer drug use risk" category. The remaining 254 youth $(21.1 \%)$ whose scores were " 5 " or greater on the peer drug use scale were assigned to the "high peer drug use risk" category.

\section{Sibling drug use}

Sibling drug use was assessed by four items (e.g., "I have a brother or sister who gets drunk or high.") that had four response options, ranging from "seldom or never" to "almost always." A sibling drug use scale was derived from the sum of the individual items, and it had a range of 0 to 12 (alpha = .73). Given the comparatively low prevalence of sibling drug use reported by the school-based youth, one dichotomous variable was derived that distinguished between the 981 youth
(81.5\%) reporting no sibling drug use and the remaining 222 youth (18.5\%) who reported any sibling drug use risk.

\section{Data analysis plan}

Initially, multiple logistic regression was used to assess the unadjusted association between level of peer drug use and alcohol abuse/dependence disorder status, with no peer drug use as the referent group. Subsequent models were extended to include statistical adjustment for the possible confounding influences of gender, age, and sibling drug use. Next, logistic regression models with and without adjustment for gender, age, sibling drug use, and lifetime alcohol use were used to assess the association between peer drug use and the prevalence of using illicit drugs other than alcohol three or more times in the respondent's lifetime. A similar series of logistic regression models were run to assess the association between sibling drug use and alcohol abuse/dependence disorder status as well as the association between sibling drug use and lifetime use of other illicit drugs. That is, we first used logistic regression models with and without adjustment for gender, age, and peer drug use to assess the association between any sibling drug use and alcohol abuse/dependence disorder status, with no sibling drug use as the referent group. Next, we used logistic regression models with and without adjustment for gender, age, peer drug use, and lifetime alcohol use to assess the association between sibling drug use and the prevalence of using illicit drugs other than alcohol three or more times in the respondent's lifetime. Data analyses were performed using the Windows version of SPSS 10.0 software (SPSS Inc., Chicago, Illinois, United States).

\section{RESULTS}

\section{Alcohol use/dependence status}

As anticipated, there was a positive association between peer substance use and alcohol abuse/dependence. The odds of meeting alcohol abuse/ dependence criteria increased as the level of peer substance use increased. Even with covariate adjustment for age, gender, and sibling substance use, youth with a low level of peer substance use were approximately three times as likely (95\% confidence interval $(\mathrm{CI})=1.24$ to 7.54$)$ to meet the alcohol abuse/dependence criteria when compared to youth who reported no peer drug use (Table 2). In comparison to control youth, youth exhibiting a medium level of peer substance were approximately four times as likely ( $95 \% \mathrm{CI}=1.53$ to 9.22 ) to meet alcohol abuse/dependence criteria; youth exhibiting a high level of peer substance were about eight times as likely (95\% CI $=3.31$ to 18.68$)$ to meet the criteria.

Similarly, there was a significant positive association between sibling substance use and the likelihood of exhibiting alcohol abuse/dependence (Table 2). With adjustment for age, gender, and peer drug use, youth who had a brother or sister who exhibited any substance use were about two times as likely $(95 \% \mathrm{CI}=1.02$ to 3.09$)$ to exhibit alcohol abuse/dependence.

\section{Drug use other than alcohol}

When compared to control youth, youth characterized by a low level of peer drug use did not exhibit significantly elevated rates of use of drugs other than alcohol (Table 3). This was true both with and without covariate adjustment for age, gender, sibling substance use, and lifetime alcohol use. However, youth exhibiting medium peer drug use were approximately three times as likely to use drugs other than alcohol $(95 \% \mathrm{CI}=$ 1.22 to 6.20 ), relative to control youth. Youth in the high peer drug use group were about four times as likely (95\% $\mathrm{CI}=1.86$ to 8.68$)$ to use drugs other than alcohol. Similarly, youth who had a sibling who used drugs were about 2.5 times as likely (95\% CI $=1.51$ to 4.22) to use drugs other than alcohol relative to control youth, with adjust- 
TABLE 2. Association that peer substance use and that sibling substance use had with alcohol abuse/dependence status among schoolattending youth in northern Mexico, with odds ratio (OR) and 95\% confidence interval (Cl), 1998

\begin{tabular}{|c|c|c|c|c|c|c|c|c|}
\hline & \multicolumn{2}{|c|}{ Unadjusted model } & \multicolumn{2}{|c|}{ Adjusted for gender } & \multicolumn{2}{|c|}{$\begin{array}{l}\text { Adjusted for } \\
\text { gender and age }\end{array}$} & \multicolumn{2}{|c|}{$\begin{array}{l}\text { Adjusted for gender and } \\
\text { age and either sibling } \\
\text { or peer drug use }\end{array}$} \\
\hline & OR & $95 \% \mathrm{Cl}$ & OR & $95 \% \mathrm{Cl}$ & OR & $95 \% \mathrm{Cl}$ & OR & $95 \% \mathrm{Cl}$ \\
\hline \multicolumn{9}{|c|}{ Peer substance use } \\
\hline No risk & 1.0 & - & 1.0 & - & 1.0 & - & 1.0 & - \\
\hline Low risk & 4.3 & $1.8-10.2$ & 3.6 & $1.5-8.7$ & 3.1 & $1.3-7.7$ & 3.1 & $1.2-7.5^{\mathrm{a}}$ \\
\hline \multicolumn{9}{|c|}{ Sibling substance use } \\
\hline No sibling use & 1.0 & - & 1.0 & - & 1.0 & - & 1.0 & - \\
\hline Sibling use & 2.0 & 1.3-3.3 & 1.6 & $1.0-2.6$ & 2.4 & $1.4-4.0$ & 1.8 & $1.0-3.1^{b}$ \\
\hline
\end{tabular}

${ }^{a}$ Adjusted for sibling drug use.

${ }^{\mathrm{b}}$ Adjusted for peer drug use.

ment for age, gender, peer drug use, and lifetime alcohol use.

\section{DISCUSSION}

These study findings are consistent with a large base of United States studies suggesting the significance of peer and sibling factors in the onset and development of adolescent substance use $(1,10,18-20)$. In our study, youth reporting the highest levels of peer drug use were eight times as likely to ex- hibit alcohol abuse/dependence and four times as likely to have used other drugs three or more times in their lifetime compared to the no-risk referent group, even after covariate adjustment. In comparison to control youth, youth whose siblings used drugs were about two times as likely to exhibit alcohol abuse/dependence and about 2.5 times as likely to have used drugs other than alcohol three or more times in their lifetime.

Descriptive findings are also noteworthy. For example, the rate of alco- hol abuse/dependence disorders (7.7\%) exhibited by school-based youth in this study was also consistent with previous findings from studies of schoolbased youth conducted in Mexico (4-5) and in the United States (27-28). Alcohol remains the most commonly used drug in Mexico. In addition, the use rates of drugs other than alcohol that we found were comparable to rates of drug use exhibited by school-based youth in northern Mexico reported earlier by Medina-Mora and colleagues (5). Notably, in the present study there

TABLE 3. Association that peer substance use and that sibling substance use had with use of drugs other than alcohol three or more times in lifetime among school-attending youth in northern Mexico, with odds ratio (OR) and 95\% confidence interval (Cl), $1998^{a}$

\begin{tabular}{|c|c|c|c|c|c|c|c|c|c|c|}
\hline & \multicolumn{2}{|c|}{ Unadjusted model } & \multicolumn{2}{|c|}{ Adjusted for gender } & \multicolumn{2}{|c|}{$\begin{array}{c}\text { Adjusted for } \\
\text { gender and age }\end{array}$} & \multicolumn{2}{|c|}{$\begin{array}{l}\text { Adjusted for gender, } \\
\text { age, and either sibling } \\
\text { or peer drug use }\end{array}$} & \multicolumn{2}{|c|}{$\begin{array}{l}\text { Adjusted for gender, } \\
\text { age, either sibling or } \\
\text { peer drug use, and } \\
\text { lifetime alcohol use }\end{array}$} \\
\hline & OR & $95 \% \mathrm{Cl}$ & OR & $95 \% \mathrm{Cl}$ & OR & $95 \% \mathrm{Cl}$ & OR & $95 \% \mathrm{Cl}$ & OR & $95 \% \mathrm{Cl}$ \\
\hline \multicolumn{11}{|c|}{ Peer substance use } \\
\hline No risk & 1.0 & - & 1.0 & - & 1.0 & - & 1.0 & - & 1.0 & - \\
\hline Low risk & 2.0 & $0.9-4.6$ & 2.0 & $0.9-4.5$ & 2.0 & $0.9-4.5$ & 1.9 & $0.8-4.3^{b}$ & 1.8 & $0.8-4.0^{b}$ \\
\hline Medium risk & 3.7 & $1.7-8.0$ & 3.5 & $1.5-7.7$ & 3.5 & $1.6-7.8$ & 2.9 & $1.3-6.6^{b}$ & 2.8 & $1.2-6.2^{b}$ \\
\hline High risk & 6.8 & $3.3-13.9$ & 6.3 & $3.0-13.1$ & 6.3 & $3.0-13.1$ & 4.7 & $2.2-10.1^{b}$ & 4.0 & $1.9-8.7^{b}$ \\
\hline \multicolumn{11}{|c|}{ Sibling substance use } \\
\hline No sibling use & 1.0 & - & 1.0 & - & 1.0 & - & 1.0 & - & 1.0 & - \\
\hline Sibling use & 3.8 & $2.3-6.0$ & 3.5 & $2.2-5.7$ & 3.6 & $2.2-5.8$ & 2.8 & $1.7-4.7^{c}$ & 2.5 & $1.5-4.2^{c}$ \\
\hline
\end{tabular}


was much greater variability in responses for peer drug use than in responses for sibling drug use. To some extent, this lack of variability in sibling substance use might account for the modest albeit significant associations between sibling substance use and youth alcohol and other drug use problem severity.

The significance of our findings is underscored by the high rates of immigration to the United States by persons from the northern region of Mexico. To the extent that common drug abuse risk factors are identified across cultural and ethnic boundaries, drug prevention programs might be developed that can benefit a greater proportion of at-risk youth in Mexico as well as those who emigrate from Mexico to the United States (1-2, 10, 18-20).

In the United States, peer group interventions and substance treatment tend to have iatrogenic effects. That is, interventions implemented among youth in the United States have shown that high-risk youth in particular are vulnerable to heightened deviant behavior when exposed to other substance-abusing and deviant youth $(29,30)$. On the other hand, family-centered interventions have been proven to be effective in mitigating the negative influences of both peer and sibling substance use. For example, Dishion and colleagues found that a familycentered intervention implemented in a public middle school reduced initiation of substance use among students, regardless of level of risk (31-32).

Given the importance of the family in Mexican culture, family-centered interventions for Mexican youth in Mexico and those who have immigrated to the United States may prove most effective. Adolescents in the northern border states of Mexico may especially benefit from family-centered interventions; youth in those states tend to have higher rates of drug use than do adolescents in other parts of Mexico (5-6). This situation may result from the northern states' proximity to the United States and the constant exchange of cultural influences between the two nations. Further, identification of risk factors and protective factors that are unique to specific ethnic/racial groups may also help to improve extant prevention interventions that target Spanish-speaking youth who have immigrated to the United Sates.

Our study had several limitations. The generalizability of the findings is restricted as a result of the sampling procedure employed, with just one middle school and one high school included in the study. While the schools were selected at random from a city that was also randomly selected, the two schools may not be an accurate representation of school-based youth in northern Mexico and may be even less representative of youth across the entire country. The generalizability of these findings is also limited due to the inclusion of only school-attending youth. In Mexico the dropout rate after elementary school is high. For example, completion rates at the primary school level range from $80 \%$ in metropolitan areas to as low as $30 \%$ in rural areas (33). Among Mexican immigrants 25-46 years of age who are living in the United States, approximately $65 \%$ have less than a high school education (34). Little is known about substance use among individuals who drop out of school in Mexico, although there is some indication that street children use drugs more often than students (17). Clearly, studies of drug use among school dropouts in Mexico would be an important next step in understanding the role of peer and sibling drug use in that country. Still, the demographic characteristics of the students in the schools in this study were comparable to the demographic characteristics of other youth enrolled in urban schools in northern border states (5).

Since this study analyzed cross-sectional data, the causal relationships that peer drug use and sibling drug use have with adolescent drug use cannot be determined. However, a number of longitudinal studies conducted in the United States have suggested that peer and sibling drug use precede the development of high levels of adolescent alcohol use and other drug use $(35,36)$.

Drug abuse prevention efforts in Mexico and the United States may benefit from future studies that examine the specific mechanisms whereby drug abuse risk factors, such as sibling and peer drug use, lead to the development of drug abuse among youth. Similarly, individual characteristics that protect youth against the development of drug abuse despite the presence of identified risk factors are largely unknown for school-based youth in Mexico and are thus worthy of study.

Acknowledgements. This research was supported by a grant from the Division of Epidemiology, University of Minnesota Scientist Development Award from the National Institute on Drug Abuse DA (00254).

\section{REFERENCES}

1. Epstein JA, Williams C, Botvin GJ. How universal are social influences to drink and problem behaviors for alcohol use? A test comparing urban African-American and Caribbean-American adolescents. Addict Behav. 2002;27:75-86

2. De Micheli D, Formigoni MLOS. Are reasons for the first use of drugs and family circum- stances predictors of future use patterns? Addict Behav. 2002;27:87-100.

3. McCuller WJ, Sussman S, Dent CW, Teran L. Concurrent prediction of drug use among high-risk youth. Addict Behav. 2001;26:13724.

4. Medina-Mora ME, Rojas E, Galván J, Juárez F, Berenzon S, Carreño S, et al. Drug use among
Mexican student youth. In: Proceedings from the 1992 meeting of the Community Epidemiology Work Group. Silver Spring: Johnson, Bassin, Shaw. 1996: Pp. 483-94.

5. Medina-Mora ME, Villatoro J, Rojas E. Drug use among students in Mexico's northern border states. In: Proceedings from the 1992 meeting of the Community Epidemiology Work 
Group. Silver Spring: Johnson, Bassin, Shaw. 1996: Pp. 367-79.

6. Félix-Ortiz M, Velázquez JAV, Medina-Mora ME, Newcomb MD. Adolescent drug use in Mexico and among Mexican-American adolescents in the United States: environmental influences and individual characteristics. Cultur Divers Ethnic Minor Psychol. 2001;7(1): 27-46.

7. Velez CN, Ungemack JA. Psychosocial correlates of drug use among Puerto Rican youth: generational status differences. Soc Sci Med. 1995;40(1):91-103.

8. Villatoro JA, Medina-Mora ME, Juárez F, Rojas E, Carreño S, Berenzon S. Drug use pathways among high school students of Mexico. Addiction. 1998;93(10):1577-88.

9. Medina-Mora ME, Villatoro JA, López EK, Berenzon S, Carreño S, Juárez F. Los factores que se relacionan con el inicio, el uso continuado y el abuso de sustancias psicoactivas en adolescentes mexicanos. Gac Med Mex. 1995;131(4):383-93.

10. Mason AW, Windle M. Family, religious, school and peer influences on adolescent alcohol use: a longitudinal study. J Stud Alcohol. 2001;62(1):44-53.

11. Paulson MJ, Coombs RH, Richardson MA. School performance, academic aspirations, and drug use among children and adolescents. J Drug Educ. 1990;20(4):289-303.

12. Stoep AV, Weiss NS, McKnight B, Beresford SAA, Cohen P. Which measure of adolescent psychiatric disorder-diagnosis, number of symptoms, or adaptive functioning best predict adverse young adult outcomes? J Epidemiol Community Health. 2002;56(1):56-65.

13. Deas-Nessmith D, Brady K, White R, Campbell S. HIV risk behaviors in adolescent and substance abusers. J Subst Abuse Treat. 1999; 16(2)169-72.

14. Shope JT, Waller PF, Raghunathan TE, Patil $\mathrm{SM}$. Adolescent antecedents of high-risk driving behavior into young adulthood: substance use and parental influences. Accid Anal Prev. 2001;33(5):649-58

15. Tapert SF, Aarons GA, Sedlar GR, Brown SA. Adolescent substance use and sexual risktaking behavior. J Adolesc Health. 2001;28(3): 181-9.

16. Hawkins JD, Catalano RF, Miller JY. Risk and protective factors for alcohol and other drug problems in adolescence and early adulthood: implications for substance abuse prevention. Psychol Bull. 1992;12(1):64-105.

17. Juárez F, Medina-Mora E, Berenzon S, Villatoro JA, Carreño S, López EK, Galván J, et al. Antisocial behavior: its relation to selected sociodemographic variables and alcohol and drug use among Mexican students. Subst Use Misuse. 1998;33(7):1437-59.

18. Kosterman R, Hawkins JD, Guo J, Catalano RR, Abbott RD. The dynamics of alcohol and marijuana initiation: patterns and predictors of first use in adolescence. Am J Public Health. 2000;90(3):360-6.

19. Zhang L, Welte JW, Wiczorek WF. Peer and parental influences on male adolescent drinking. Subst Use Misuse. 1997;32(14):2121-36.

20. Swadi $H$. Individual risk factors for adolescent substance abuse. Drug Alcohol Depend. 1999;55:209-24.

21. Nazar-Beutelspacher A, Tapia-Conyer R, VillaRomero A, León-Alvarez G, Medina-Mora ME, Salvatierra-Izaba B. Factores asociados al consumo de drogas en adolescentes de áreas urbanas de México. Salud Publica Mex. 1994 36(6):646-54

22. Johnston LD, O'Malley DM, Bachman JG. Monitoring the Future national survey results on drug use, 1975-2000. Volume I. Secondary school students. Bethesda: National Institute on Drug Abuse; 2000. (NIH Publication No. 01-4924).

23. Latimer WL, O'Brien MS, Vasquez MA, Medina-Mora ME, Rio-Bedoya C, Floyd L. Adolescent substance abuse in Mexico, Puerto Rico, and the United States: effect of anonymous vs. confidential survey formats. J Child Adolesc Subst Abuse. Forthcoming 2004.

24. Winters KC, Henly GA. Personal Experience Inventory test and manual. Los Angeles: Western Psychological Services; 1989.

25. Winters KC, Stinchfield RD, Henly GA. Convergent and predictive validity of scales measuring adolescent substance abuse. J Child Adolesc Subst Abuse. 1996(5):37-55.

26. Winters KC, Henly GA. Adolescent Diagnostic Interview schedule and manual. Los Angeles: Western Psychological Services; 1993.

27. Harrison PA, Fulkerson JA, Beebe TJ. DSM-IV substance use disorder criteria for adolescents: a critical examination based on a statewide school survey. Am J Psychiatry. 1998;155:486-92.
28. Hartwell S, Ungemack J, Babor TF. Adolescent substance abuse treatment needs assessment: the 1995 adolescent alcohol and drug use school survey. Hartford, Connecticut, United States: Department of Mental Health and Addiction Services; 1996.

29. Dishion TJ, McCord J, Poulin F. When interventions harm. Peer groups and problem behavior. Am Psychol. 1999;54(9):755-64.

30. Dishion TJ, Bullock BM, Granic I. Pragmatism in modeling peer influence: dynamics, outcomes, and change processes. Dev Psychopathol. 2002;14(4):969-81.

31. Spoth RL, Kavanagh KA, Dishion TJ. Familycentered preventive intervention science: toward benefit to larger populations of children, youth, and families. Prev Sci. 2002;3(3):14552.

32. Dishion TJ, Kavanagh K, Schneiger A, Nelson S, Kaufman NK. Preventing early adolescent substance use: a family-centered strategy for the public school. Prev Sci. 2002;3(3):191-201.

33. Japan International Cooperation Agency. Country WID profile: Mexico. 1999 December. Available from: http://www.jica.go.jp/ english/global/wid/report/pdf/e99mex.pdf [Internet site]. Accessed 28 August 2003.

34. Camarota SA. Immigration from Mexico: assessing the impact on the United States. Center for Immigration Studies. 2001 July. Available from: http://www.cis.org/articles/ 2001/mexico/mexico.pdf [Internet site]. Accessed 28 August 2003.

35. Latimer WW, Winters KC, Stinchfield R, Traver RE. Demographic, individual, and interpersonal predictors of adolescent alcohol and marijuana use following treatment. Psychol Addict Behav. 2000;4(2):162-73.

36. Needle R, McCubbin H, Wilson M, Reineck R, Lazar A, Mederer H. Interpersonal influences in adolescent drug use-the role of older siblings, parents, and peers. Int J Addict. 1986; 21(7):739-66.

Manuscript received 15 January 2003. Revised version accepted for publication on 1 October 2003 
RESUMEN Objectivo. Examinar en qué medida el uso de drogas por los pares y hermanos es factor pronóstico del abuso o la dependencia del alcohol y del uso de drogas distintas del alcohol en escolares mexicanos.

\section{El uso de sustancias por pares y hermanos como factor pronóstico del uso de sustancias por adolescentes en México}

Métodos. Se recolectaron datos acerca de 1203 estudiantes de los últimos años de primaria y de secundaria en el norte de México en mayo de 1998. La participación en el estudio fue voluntaria, y las respuestas fueron confidenciales. Mediante análisis de regresión logística se estimó la asociación entre el uso de drogas por los pares y hermanos por un lado, y por el otro el diagnóstico de abuso o dependencia del alcohol y el uso de sustancias distintas del alcohol en algún momento de la vida.

Resultados. Los estudiantes cuyos hermanos o pares ingerían bebidas alcohólicas y consumían otras drogas mostraron mayores probabilidades de satisfacer los criterios estándares de abuso o dependencia del alcohol, según los define el Manual diagnóstico y estadístico de enfermedades mentales, cuarta edición (MDE-IV), y de haber consumido drogas distintas del alcohol. Después de controlado el efecto de posibles factores de confusión, los adolescentes con los niveles más altos de abuso de sustancias por parte de sus pares se mostraron ocho veces más propensos a satisfacer los criterios de abuso o dependencia del alcohol y cuatro veces más propensos a consumir otros tipos de sustancias. Los adolescentes cuyos hermanos consumían drogas tenían una probabilidad dos veces mayor de satisfacer los criterios de abuso o dependencia del alcohol y una probabilidad 2,5 veces mayor de consumir drogas en comparación con jóvenes cuyos hermanos no consumían ninguna sustancia.

Conclusiones. Tal como indican otros resultados obtenidos con adolescentes en Estados Unidos de América, el uso de sustancias por los pares y hermanos es un factor de riesgo de consumo de sustancias en escolares en México. Estos últimos podrían beneficiarse de estrategias preventivas cuya eficacia en jóvenes estadounidenses se haya demostrado.

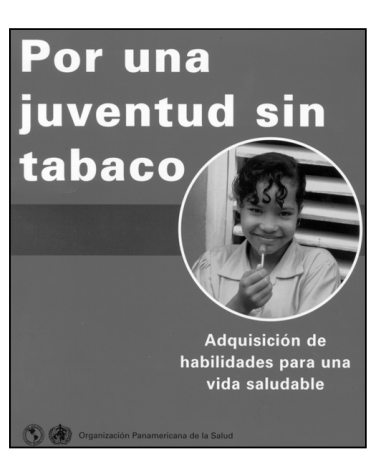

2001, 72p., ISBN 9275315795 Código: PC 579

Precio US\$14.00

\section{Por una juventud sin tabaco}

En la primera parte del libro se muestran los problemas fundamentales del consumo de tabaco, especialmente para la juventud. Se revisan temas relacionados con la prevención de las enfermedades relacionadas con el tabaco en los países de la Región y se describen los aspectos más eficaces de los diferentes métodos usados para su prevención. En la segunda, se presentan los enfoques teóricos y prácticos del programa de prevención del hábito de fumar conocido como "Habilidades para la vida", que alecciona a los jóvenes para que sean capaces de resistir las presiones sociales y de los medios de comunicación que los incitan a fumar.

Esta publicación está destinada a los profesionales de la salud, los planificadores de programas, los educadores, los encargados de formular las políticas y los grupos e instituciones que participan en la lucha contra el tabaquismo. En ella encontrarán información muy útil sobre la situación del tabaquismo en la Región, así como pautas para planificar y desarrollar programas de prevención del abuso de drogas, similares al de "Habilidades para la vida", que se adapten a las necesidades específicas de la Región y que sean un arma poderosa para la reducción de la carga evitable de muertes y discapacidades relacionadas con el tabaco. 